\title{
POSSIBILIDADE DE LETRAMENTO EM LÍNGUAS INDÍGENAS
}

\author{
Maria do Socorro Pimentel da Silva \\ Núcleo Takinahakỹ de Formação Superior de \\ Professores Indígenas/Faculdade de Letras/UFG
}

\section{RESUMO}

O objetivo deste texto é ampliar o debate sobre 'letramento em línguas indígenas' e sua função sociocultural na vitalidade e manutenção do patrimônio cultural e natural dos povos indígenas. E significa, em primeira instância, entender a diferença entre os processos de letramento em língua portuguesa e nas línguas indígenas. Nestas, uma das reivindicações de uso da escrita é a de se constituir em um espaço memorial para guardar o patrimônio cultural, a criatividade dos povos indígenas, as riquezas das culturas e o conhecimento tradicional indígena sobre a natureza. Em situação de perda acelerada da língua materna indígena, a escrita tem funcionado como um recurso de movimentação a favor da saúde das línguas na medida em que aumenta a consciência linguística dos falantes do risco de extinção desse bem cultural, que acontece, na maioria vezes, pela falta de escolaridade nessas línguas.

PALAVRAS-CHAVE: Letramento. Línguas indígenas. Vitalidade. Patrimônio cultural.

\section{ABSTRACT}

This paper aims at broaden the debate on 'literacy in indigenous languages' and their socio-cultural role in the vitality and maintenance of cultural and natural heritage of indigenous peoples. First of all, it means understanding the difference between literacy processes in Portuguese and indigenous languages. In these, one of the written use of claims is to constitute a memorial space to save the cultural heritage, creativity of indigenous peoples, the wealth of cultures and traditional indigenous knowledge about nature. In a rapid loss of 
indigenous mother tongue, writing has worked as a drive resource for the health of languages in that it increases the linguistic consciousness of speakers of endangered cultural property of that, what happens in most cases, the lack of education in these languages.

KEYWORDS: Literacy. Indigenous languages. Vitality. Cultural heritage.

\section{UM POUCO DE CONVERSA SOBRE LETRAMENTO EM LÍNGUAS INDÍGENAS}

O objetivo deste texto é ampliar o debate sobre 'letramento em línguas indígenas' e sua função sociocultural na vitalidade e manutenção do patrimônio cultural e natural dos povos indígenas. E significa, em primeira instância, entender a diferença entre os processos de letramento em língua portuguesa e nas línguas indígenas. Nestas, uma das reivindicações de uso da escrita é a de se constituir em um espaço memorial para guardar o patrimônio cultural, a criatividade dos povos indígenas, as riquezas das culturas e o conhecimento tradicional indígena sobre a natureza. Em situação de perda acelerada da língua materna indígena, a escrita tem funcionado como um recurso de movimentação a favor da saúde das línguas na medida em que aumenta a consciência linguística dos falantes do risco de extinção desse bem cultural, que acontece, na maioria vezes, pela falta de escolaridade nessas línguas.

As línguas indígenas, no cenário nacional, são consideradas como línguas de menor prestígio social, econômico, político e epistêmico, realidade que impõe aos seus falantes sentimentos de inferioridade com relação ao seu uso e transmissão às novas gerações. Exemplifico essa atitude com a fala de uma índia Macuxi, em comunicação pessoal, durante uma etapa do curso de Licenciatura Intercultural do Núcleo Insikiram da Universidade Federal de Roraima, quando me revelou que, por conta do preconceito linguístico, não ensinou a seus filhos a sua língua materna, mas que agora, devido ao valor político dado à língua na formação dos professores, estava transmitindo-a aos seus netos. Um professor indígena do curso do Magistério Indígena da SEDUC do Estado do 
Tocantins perguntou-me em sala de aula: 'o que ensino na minha língua materna depois da alfabetização’? Em síntese, essas questões revelam um cenário histórico desfavorável às línguas indígenas, mas também as inquietações dos seus falantes frente às novas conquistas no campo da educação e dos direitos linguísticos.

Ou seja, discutir letramento em línguas indígenas é um grande desafio. Um deles é o de colocar a escrita para exercer o papel social de vitalizar a oralidade das línguas indígenas. $\mathrm{O}$ outro, além de muitos outros, é o de atender à emergência de aumentar a autoestima dos falantes como um meio para retirar as línguas do risco de extinção. Uma língua torna-se ameaçada de desaparecer quando está em via de deixar de ser aprendida pelos jovens. Uma língua fica forte quando sua transmissão é garantida, e, pelo que tenho percebido na atualidade, isso deve acontecer por meio das modalidades oral e escrita, mas sem dicotomias, e com ajuda da escola e da comunidade.

O estudo com os indígenas no Curso de Educação Intercultural da UFG tem me mostrado que, quando as línguas indígenas não são usadas na escola apenas como recurso pedagógico de tradução, mas como línguas de conhecimento, seu prestígio aumenta frente aos seus usuários. Além disso, amplia-se o debate sobre as funções sociais da escrita em suas línguas maternas, como, por exemplo: (1) contribuir com a vitalidade da língua e das linguagens culturais; (2) vitalizar os espaços culturais; (3) documentar saberes; (4) fortalecer a memória; (5) incentivar a transmissão dos saberes tradicionais de uma geração a outra; (6) trazer lembranças dos conhecimentos ancestrais; (7) gerar motivo de conversas entre gerações e na mesma geração; (8) guardar conhecimentos; (9) implementar políticas de modernização linguística para fortalecer a tradição, como, por exemplo, políticas de criação de palavras novas para nomear realidades novas; (10) fortalecer a escola e vinculá-la a outros espaços educativos das comunidades; (11) fortalecer a educação própria dos indígenas; (12) contribuir para movimentar/atualizar a cultura materna; (13) prestigiar as epistemologias indígenas; (14) divulgar conhecimentos; (15) pesquisar conhecimentos etc.

O letramento em línguas indígenas, portanto, não se enquadra nas tipologias dos gêneros textuais da língua portuguesa, por exemplo, mas em aumentar as potencialidades de seus usos entre 
gerações nos espaços cotidianos e especializados. O importante é que o indígena sinta dignidade e prestígio ao falar, ler e escrever em sua língua. Nesse sentido, é necessário buscar referências de letramento que correspondam a programas de enriquecimento das línguas indígenas e de um bilinguismo ativo, plural, o que nos obriga a buscar novas áreas de investigação. A ideia de Temas Contextuais, que se ancora na noção de transdisciplinaridade, reivindica a adoção de um bilinguismo epistêmico (Pimentel da Silva, 2015), sem hierarquia, buscando derrubar a colonialidade das línguas e dos saberes indígenas.

Nos Temas Contextuais há espaço para os usos das línguas nas modalidades oral e escrita tanto nas Ciências da Linguagem, quanto nas Ciências da Natureza, e nas Ciências da Cultura. Os temas interculturais são reconhecidos pelas suas próprias características e favorecem os usos da língua portuguesa e das indígenas, sem a necessidade de tradução, mas de valorização dos idiomas. Se os conhecimentos dos Temas Contextuais são de pertencimentos das cosmologias indígenas, por exemplo, inegavelmente a língua preferida para o estudo e o ensino é a indígena. Muitos temas desses sequer têm como serem traduzidos: muitos são sagrados, outros são segredos. Outros são corrompidos, quando traduzidos.

As ações de letramento nas comunidades indígenas devem ter em mente a vitalidade das línguas maternas ancestrais. Segundo o documento da UNESCO (2003, p. 02): “[...] a extinção de uma língua significa a perda irrecuperável de saberes únicos, culturais, históricos e ecológicos. Cada língua é uma expressão insubstituível da experiência humana do mundo." Uma vez entendidas quais são as metas do planejamento linguístico de letrar em línguas indígenas, coloco aqui, como exemplo, uma ação de sucesso, programada e realizada com os universitários indígenas, a maioria professores em suas comunidades. Sinta-se à vontade para experimentar e fazer as coisas à sua maneira ou adotar a programação a seguir para debater o letramento em línguas indígenas. Participaram da atividade os seguintes povos indígenas: Karajá, Javaé, Krikati, Gavião, Xerente, Tapirapé, Guajajara, Apinajé e Krahô. Todos se envolveram com a organização e realização da 'Feira das Línguas Indígenas'. Esse evento é parte do programa do Tema Contextual 'Fronteiras Linguísticas: 
Vida e morte de línguas' do Curso de Educação Intercultural da UFG, que se realizou na etapa julho-agosto de 2013 no Núcleo Takinahakỹ de Formação Superior Indígena.

\section{FEIRA DAS LÍNGUAS INDÍGENAS}

Professor José Cohxyj Krikati e professora Adeilda Katoaxowa Tapirapé, apresentando os objetivos da Feira.

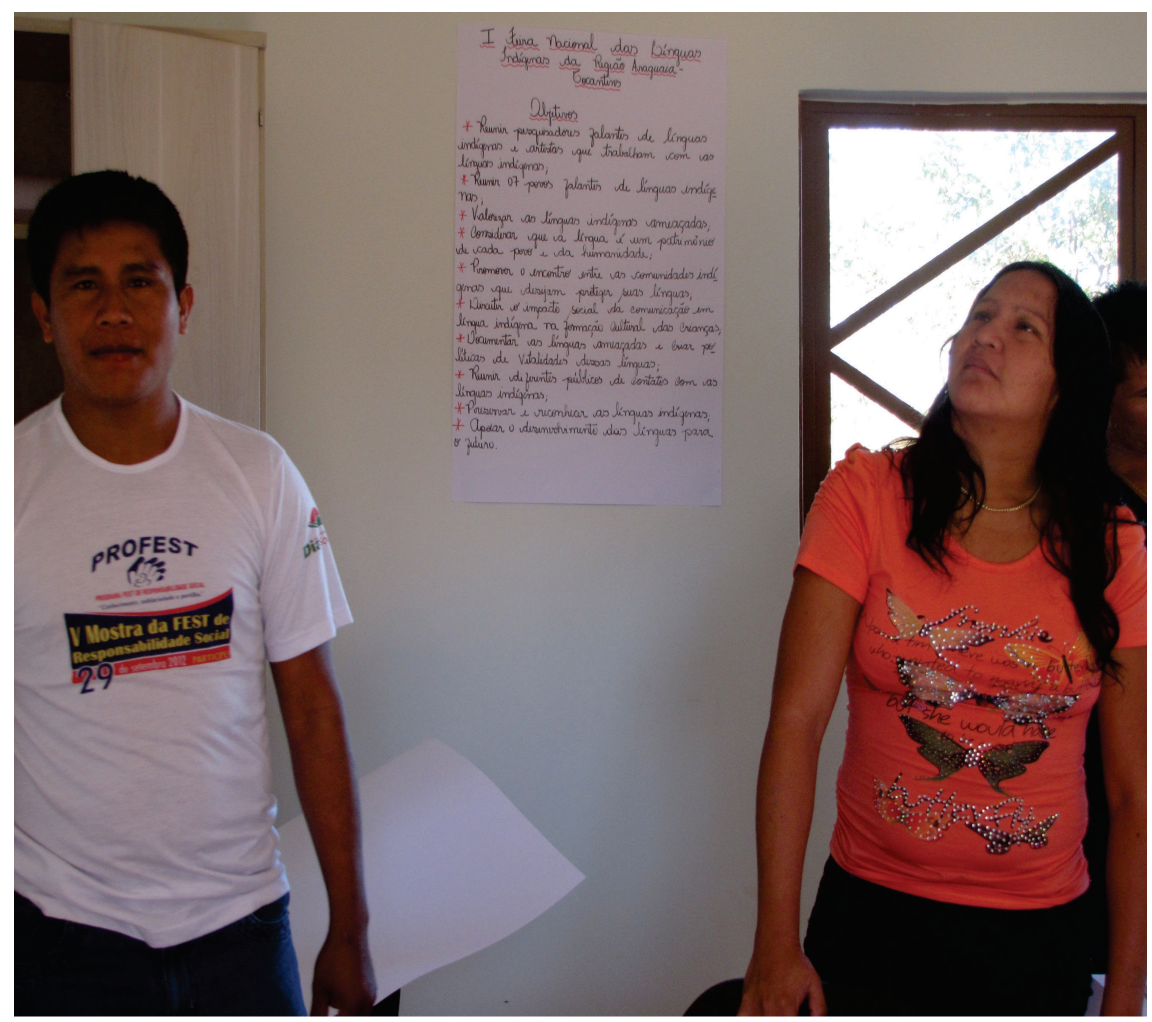




\section{CARTAZ DA FEIRA SOBRE LETRAMENTO CULTURAL}

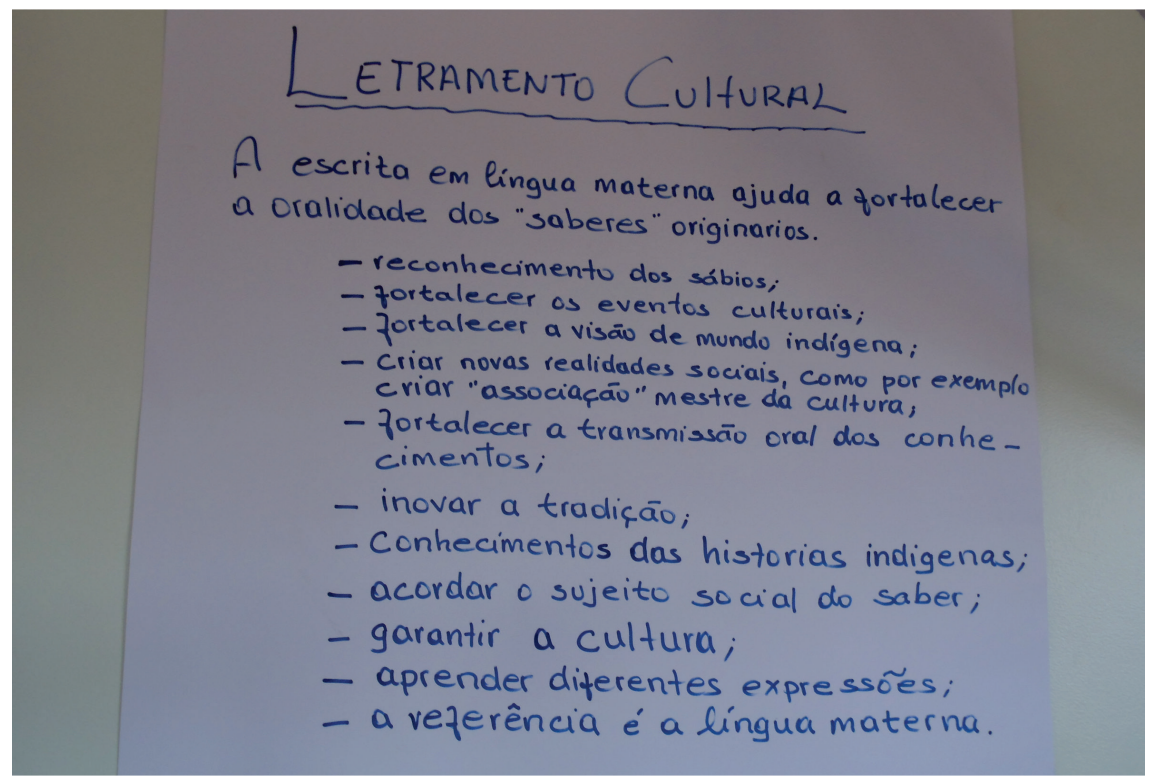

Nesses termos, a escola é lugar excelente para motivar a produção escrita em línguas indígenas desde que esteja inserida em políticas de valorização cultural.

Professores Tebutxiwè Karajá, Beti Karajá, Nilson Brito Xerente, Silvia Letícia Gomes da Silva Xerente e José Pedro Guajajara, produzindo textos para a Feira em suas línguas maternas. 


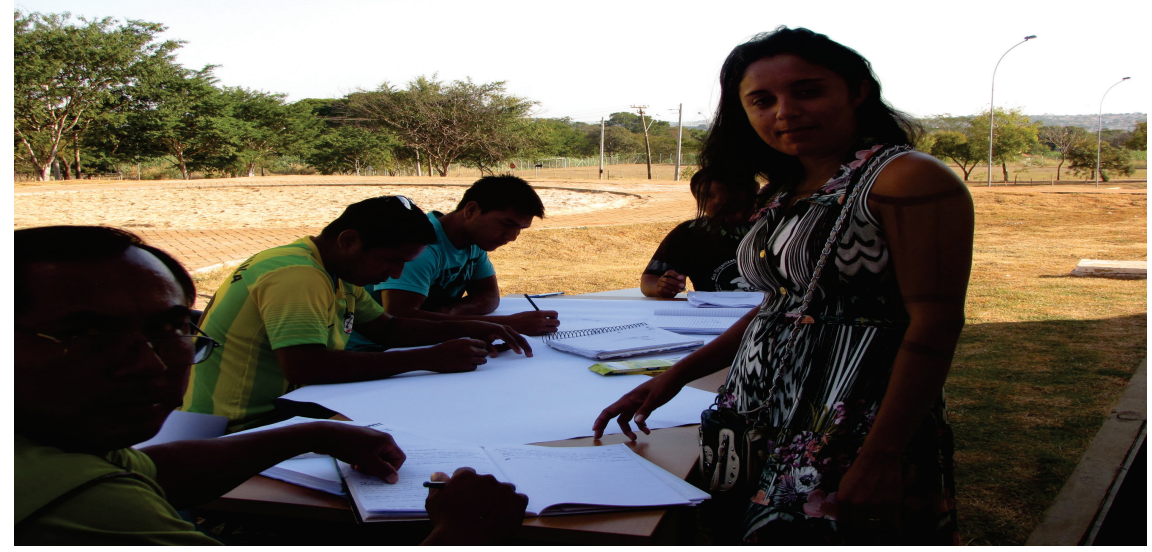

Professores Edivaldo Paraty Krahô e Joel Marcos Cuxy Krahô, escrevendo em sua língua materna para a Feira.

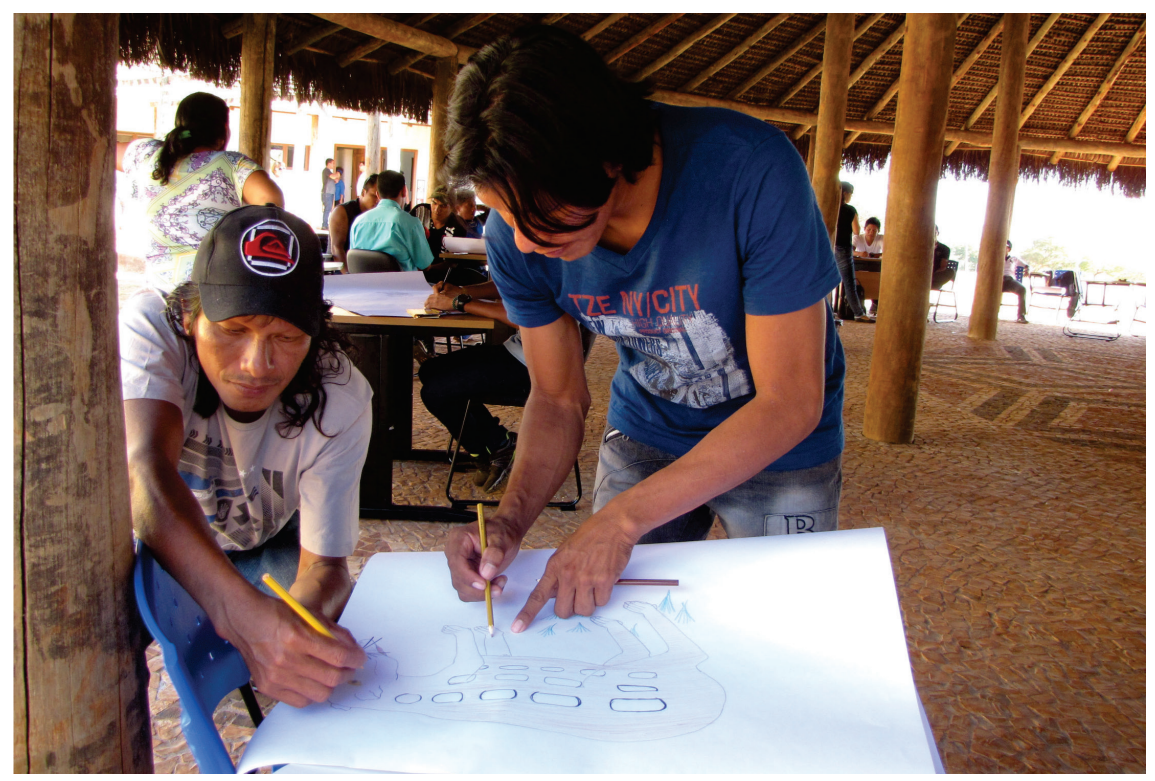

Professores Tebutxiwè Karajá, Beti Karajá, Nilson Brito Xerente, Silvia Letícia Gomes da Silva Xerente e José Pedro Guajajara, produzindo textos para a Feira em suas línguas maternas. 


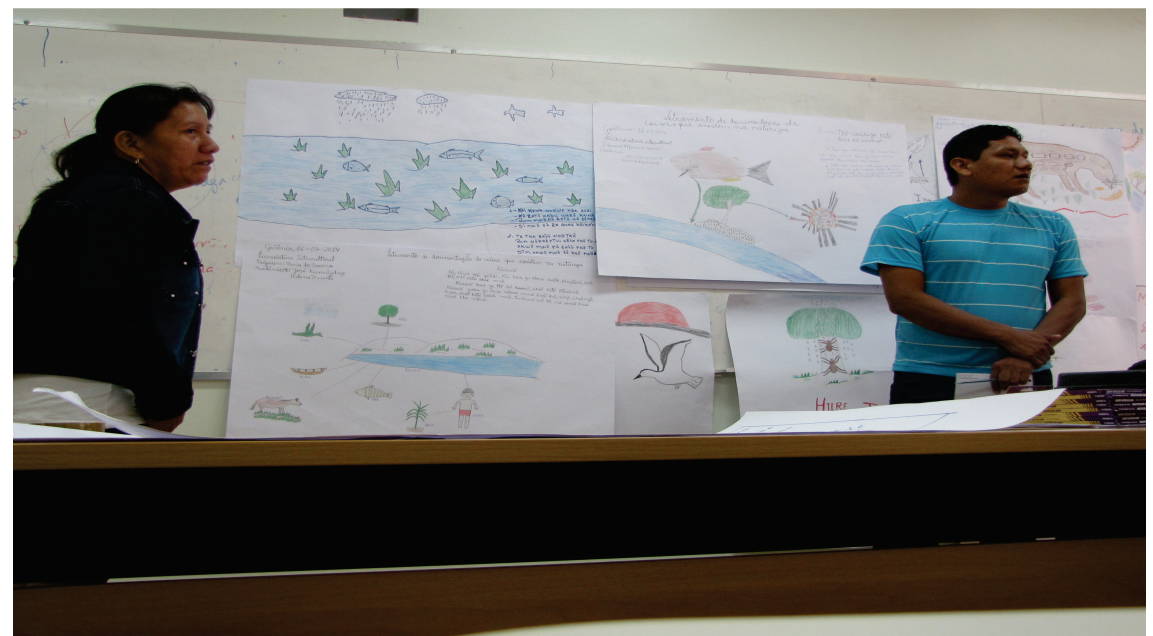

Exposição de textos musicais em várias línguas na Feira das línguas inidígenas.

Todos homenageiam a natureza. A grande maioria são textos de músicas. Professora Helena Krukwane Xerente e Professor Armando Sõpre Xerente, comentando a exposição dos temas da Feira.

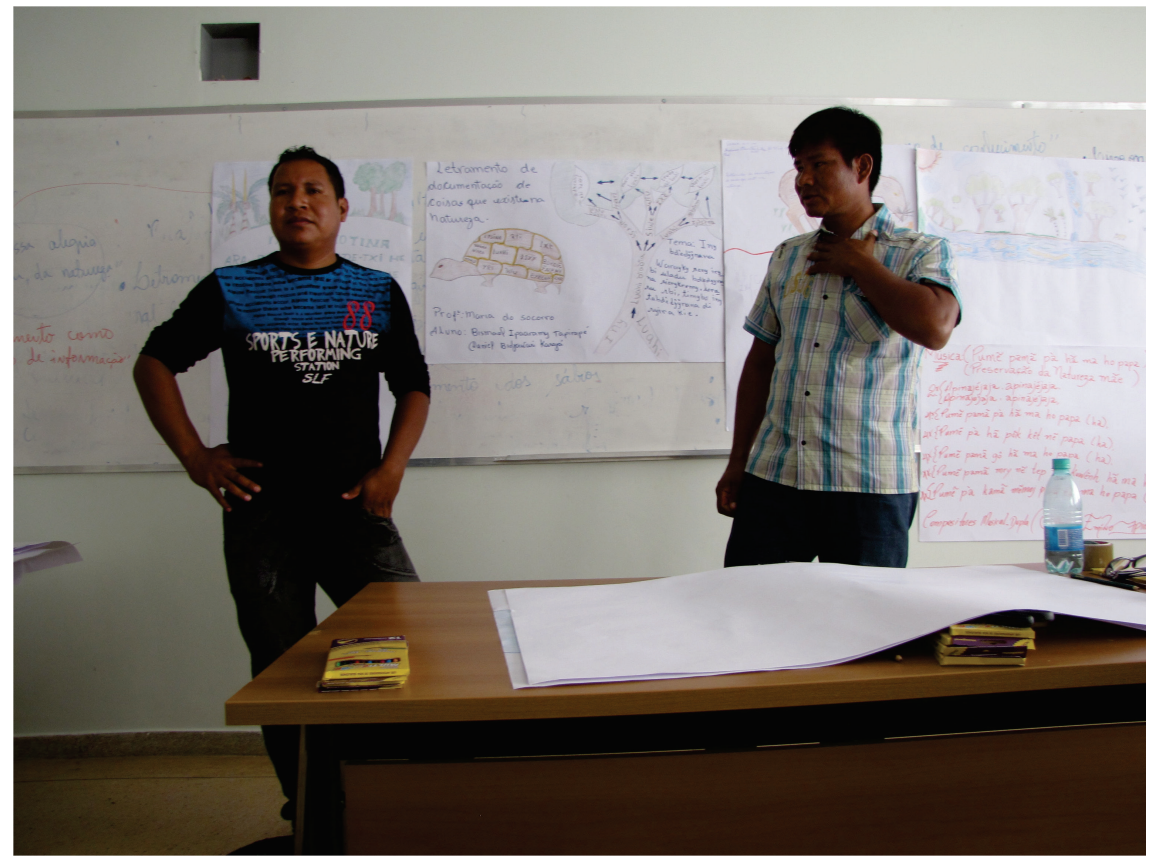




\section{DOCUMENTAÇÃO DE SABERES EM LÍNGUAS MATERNAS}

\section{DOCUMENTAÇÃO DE ARTESANATO EM LÍNGUA TAPIRAPÉ}

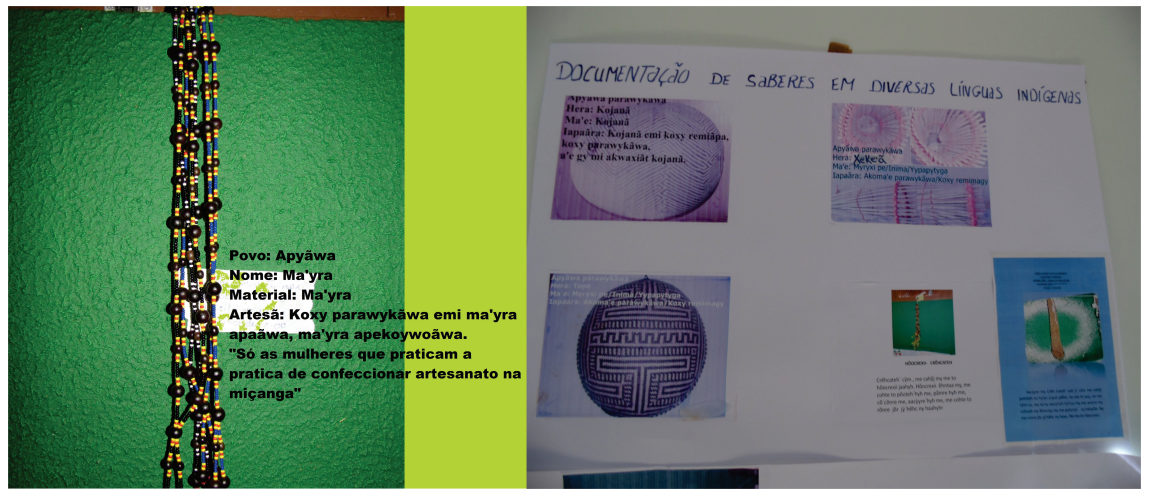

\section{CUMPRIMENTOS EM LÍNGUA KARAJÁ}
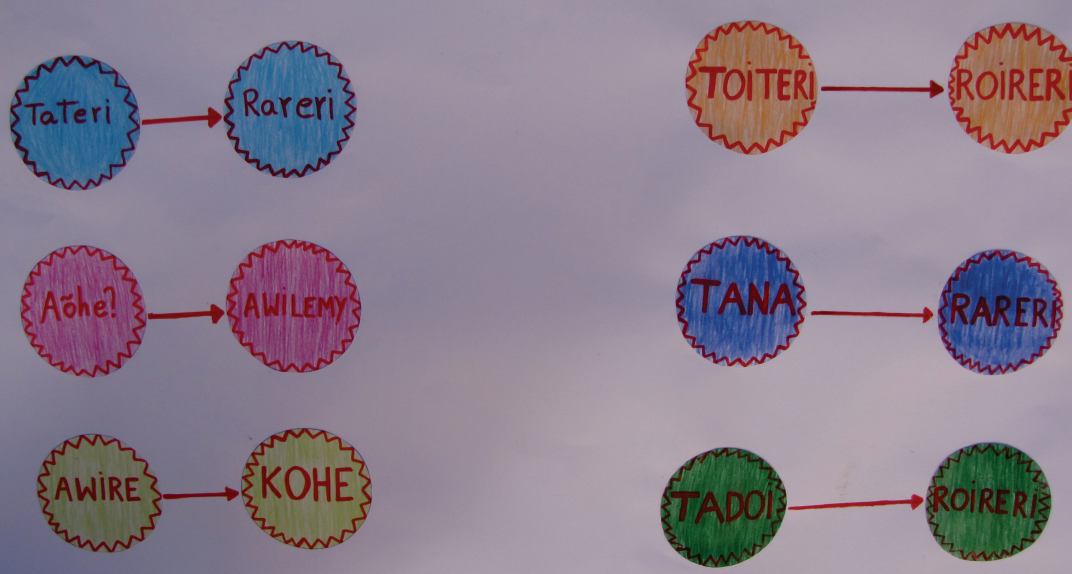


\section{CUMPRIMENTOS EM LÍNGUA GUAJAJARA}

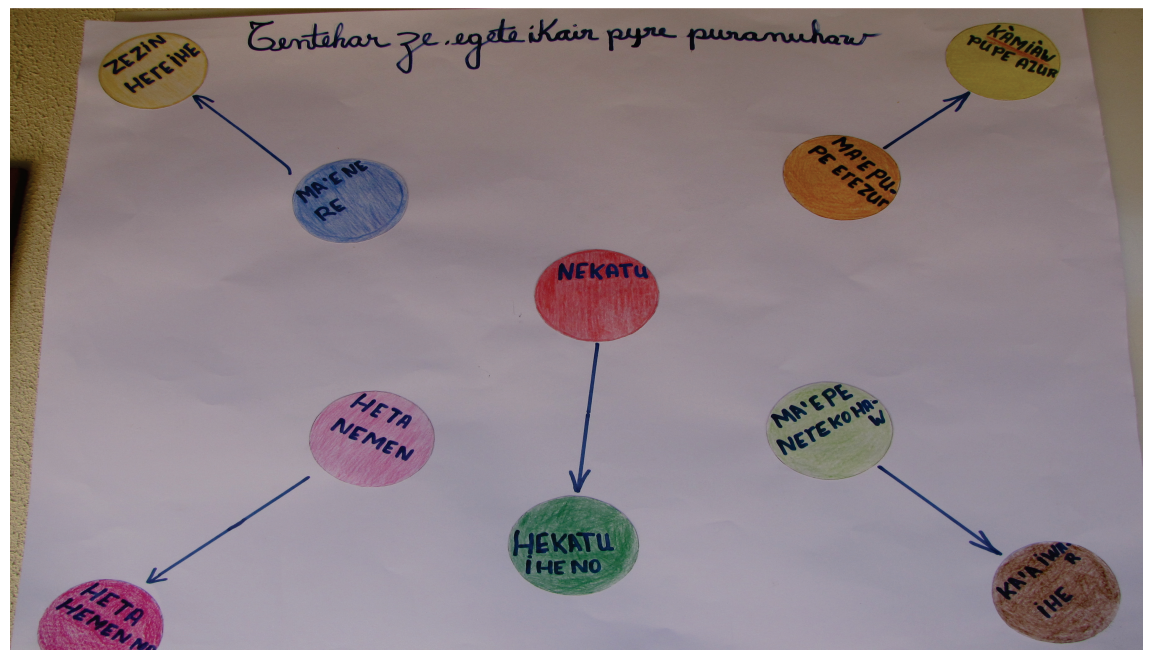

\section{ESCRITA PARA RELEMBRAR CONHECIMENTOS}

O Projeto de Educação e Cultura Indígena que se realiza em Buridina, comunidade Karajá situada no estado de Goiás, é um exemplo de luta para que as gerações não percam o patrimônio cultural da língua materna ancestral. Essa comunidade usa a escrita nessa língua para vitalizá-la. Foi o que aconteceu quando o livro 'Linguagem especializada: mitologia Karaja' foi distribuído para as famílias em Buridina. Na sua leitura, as famílias se juntaram - filhos, netos, avós, pais e mães - para comentarem as histórias que estão no livro. Avós e pais se lembraram de outras histórias, recuperaram parte de histórias esquecidas, aqueceram a memória, sentiram saudades. Lembraram dos seus avós, tios, já falecidos, mas presentes em suas memórias. Leram as histórias, e as contaram para seus filhos e netos. 


\section{VITALIZANDO CONHECIMENTOS CULTURAIS EM BURIDINA}

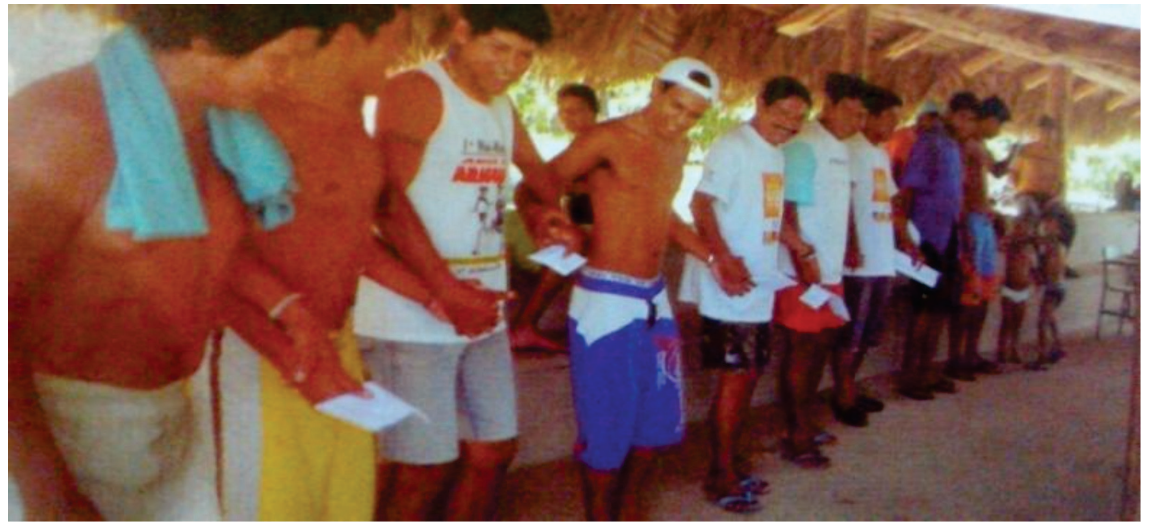

Em muitos momentos a escrita vem ajudando em reflexões importantes. O que quero falar é que a escrita está ajudando a buscar muitos saberes importantes da oralidade.

\section{A FUNÇÃO DA ESCRITA NA RETOMADA DE CONHECIMENTOS}

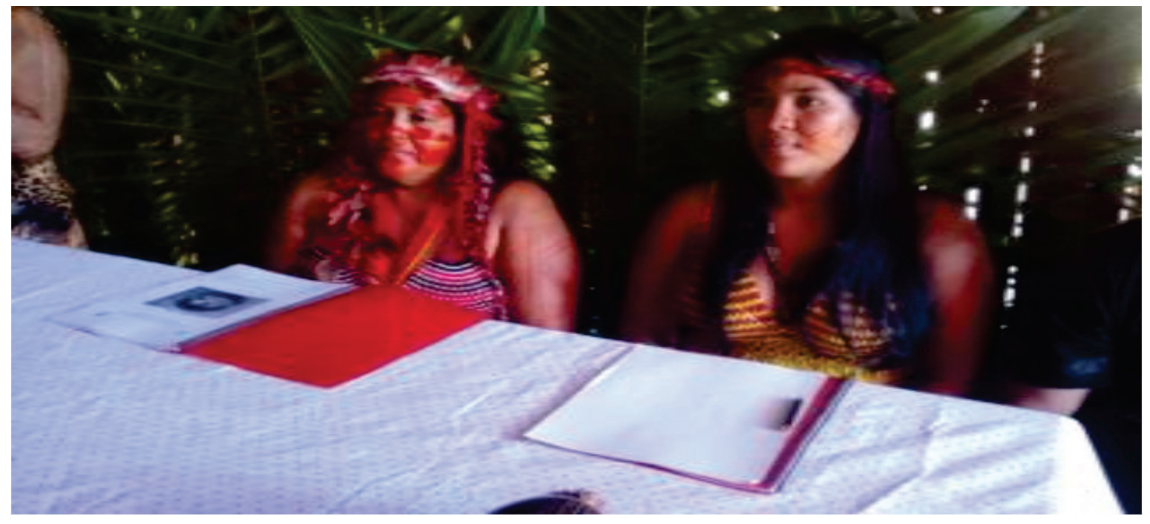

Na apresentação do projeto extraescolar, uma atividade de pesquisa, estudo e documentação de saberes indígenas do Curso de Educação Intercultural da UFG, as alunas Cíntia Guajajara e Marina Guajajara, professoras em sua comunidade, usaram muitas vezes a palavra 'retomada', como uma função de movimento da escrita em sua língua materna na atualização dos saberes. A escrita e a 
oralidade juntinhas proporcionam o acesso aos saberes indígenas por meio da pesquisa, documentação oral e escrita. É preciso considerar no letramento em línguas indígenas as necessidades e atitudes dos falantes em relação à própria língua, e o seu uso nos diferentes espaços culturais. É importante verificar quais são os valores que influenciam na manutenção de uma língua.

\section{CONSIDERAÇÕES IMPORTANTES}

Esses são apenas alguns exemplos do debate e do movimento cultural da Feira. Um movimento que pode ser feito nas comunidades. $\mathrm{O}$ evento trouxe importantes contribuições para o conhecimento necessário ao desenvolvimento de uma política linguística adequada à manutenção das línguas indígenas. Permitiu discutir a pressão em que as línguas indígenas se encontram. Roland Terborg e Laura García Landa (2011) apresentam um modelo denominado ecologia das pressões, que mostra quais atitudes, valores, crenças e ideologias exercem pressão na manutenção ou substituição de uma língua por outra. Esse estudo mostra que os falantes vivem diferentes pressões linguísticas e que essas pressões são percebidas de forma diferente pelos falantes da comunidade. Daí a importância de um estudo sociolinguístico na implementação do letramento na escola, desde a alfabetização.

$\mathrm{Na}$ organização da feira e durante a sua realização aconteceram muitos debates e análises referentes às pressões que os falantes indígenas sentem para abandonar sua língua materna. Perceberam por meio das leituras feitas que ao redor do mundo as línguas indígenas estão abrindo caminho para as coloniais e que no Brasil isso não é diferente. Discutiram, ainda, as funções sociais específicas que cada língua tem na comunidade.

Essas são pequenas contribuições que podem ajudar na contextualização do letramento, desde a alfabetização, se fundamentado de acordo com o pensamento, por exemplo, da aluna da professora Creuza Prun Krahô, que o defina como um meio de colocar as ideias nas letras. Ou como me informou Bismael Tapirapé, em comunicação pessoal, que o letramento em língua materna o tirou da escuridão em relação aos saberes próprios de sua comunidade, 
fato que aconteceu graças ao acesso, por meio da pesquisa e da documentação escrita em língua ancestral.

De modo geral, os pesquisadores indígenas estão percebendo como as mentes de seus povos foram ocupadas por um pensamento reducionista, que causou a eliminação de muitas formas de conhecimento e a dormência de outros. Pesquisas como o 'Ciclo da Vida’ revelam parte dessa situação, mas também chamam a atenção para os processos próprios de educação indígena, destacando profundo respeito pela aprendizagem em cada fase da vida, que acontece, sempre, numa abordagem transdisciplinar, ou seja, pela conexão de saberes.

Quando uma criança indígena está aprendendo, por exemplo, a confeccionar uma peça de artesanato, está também adquirindo outros conhecimentos sobre a cultura e os usos da língua materna ligados a esse fazer cultural. Princípio semelhante é o do letramento em línguas indígenas, que juntinho com a oralidade, pode se transformar em ações de vitalidade cultural, inovando as matrizes linguísticas, fontes geradoras de distintos usos das línguas indígenas.

\section{REFERÊNCIAS}

PIMENTEL DA SILVA, M. S. Impactos da educação na vitalidade do patrimônio epistêmico Iny. Goiânia: Kelps, 2015.

TERBORG, R.; GARCÍA LANDA, L. (Org.). Muerte y vitalidad de las lenguas indígenas y las presiones sobre sus hablantes. México: UNAM: CELE, 2011, 285p.

UNESCO. Vitalidad y peligro de desaparición de las lenguas. Paris, 2003. Disponível em: <http://www.unesco.org/new/fileadmin/ MULTIMEDIA/HQ/CLT/pdf/LVE_Spanish_EDITED\%20FOR\%20 PUBLICATION.pdf $>$. 